\title{
Novel Polymers Containing Fluorescein Moieties
}

\author{
Sergei Fomine, ${ }^{*}$ Armando PInedA, ${ }^{*}$ Takeshi OgaWA,* \\ Raul Perez,** and Merida Sotelo** \\ * Instituto de Investigaciones en Materiales, Universidad Nacional Autonoma de Mexico, \\ Apartado Postal 70-360, Coyoacan, Mexico DF, 04510 \\ ** Centro de Investigacion Fisica, Universidad de Sonora, \\ P.O. Box 5-088, Hermosillo, Sonora, 83190 Mexico
}

(Received January 12, 1995)

\begin{abstract}
Novel fluorescein-containing polymers and copolymers derived from novel fluorescein-containing bis-acetylene $\mathbf{3}$ were synthesized by oxidative coupling. A novel fluorescein-containing polyester was obtained by the direct polycondensation of fluorescein. All polymers synthesized were semicrystalline as observed from X-ray diffractometry but formed films of good optical quality when cast from solution. All the polymers synthesized showed luminescence both in solution and the solid state and exhibited third order nonlineal optical susceptibility of the order $10^{-10} \mathrm{esu}$.

KEY WORDS Luminescence / Fluorescein / Diacetylene-Containing Poly-

mers.
\end{abstract}

Various fluorescent polymers have been investigated in recent years. These polymers include pendent chromophore functionalized polymers and polymers having chromophores in their backbone. In particular, polymers having pendent chromophores such as poly( $N$-vinylcarbazole) have been extensively studied. ${ }^{1-3}$ Such polymers have been used as photoconductive resins. Polymers, containing photoactive moieties also find applications as fluorescent labels, scintillators and photon harvesters. ${ }^{4-7}$ These "plastic scintillators" which are conveniently processed into plates or fibers have faster response times than solid scintillators based on inorganic compounds and are thus useful in applications requiring high rates of energy analysis, such as particle accelerator. Dharia et al $^{8}$ and Matsuo et al. ${ }^{9}$ reported the synthesis and characterization of wavelength-shifting polymers based on 3hydroxyflavone and new fluorescent poly(arylene ether)s, respectively. Hargreaves and Webber studied intracoil energy transfer in antril- and fluorescein-tagged poly(vinylpyrrolidone). ${ }^{10}$

An alternative technique introducing for a fluorescent dye within the polymer entails dissolving the dye in the pure monomer and polymerizing the mixture under a slow temperature ramp. The dye is thus physically dispersed throughout the polymer. Solubility limitations constrain the concentration of the dye to several wt\%. Any supersaturated concentration of dye is likely to result in migration and phase separation.

Thus, inorganic glass filled with fluorescein show a large third order nonlinear optical susceptibility $\left(\chi^{(3)}\right)$ of 1 esu which makes fluorescein containing materials promising candidates for nonlinear optics. ${ }^{11}$ However, the optical quality of these materials is very poor because of a low solubility and miscibility of fluorescein. Making fluorescent dye an integral part of the polymer through covalent binding is an important step in the design of fluorescent materials. 
The chemical structure of fluorescein (1) is shown below:

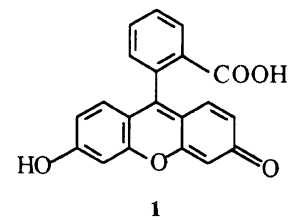

Two different synthetic approaches were employed to obtain fluorescein-containing polymers. The first is the direct polycondensation of fluorescein molecules as a monomer: using its hydroxy and carboxy groups which can be used to prepare a flourescein-containing polyester (2) (Scheme 1). The second synthesis of the polymer starts from fluorescein. The reaction of fluorescein with propargyl bromide gives fluorescein-containing bis-acetylene (3), which can be polymerized by oxidative coupling to give fluorescein-containing polymers (Scheme 2).
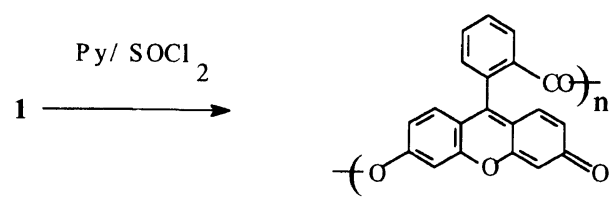

2

Scheme 1.
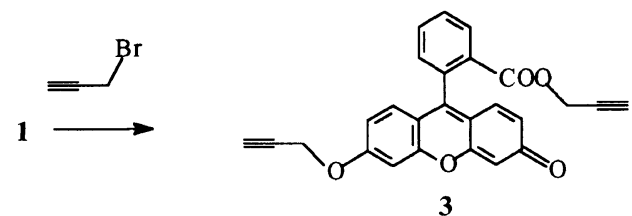

Scheme 2.

This paper, presents the synthesis and characterization of these new luminescent polymers.

\section{EXPERIMENTAL}

\section{Materials}

Pyridine (Aldrich) was distilled over $\mathrm{CaH}_{2}$. Thionyl chloride (Fluka), o-dichlorobenzene (ODCB) (Aldrich) and $N, N, N^{\prime}, N^{\prime}$-tetramethyl- ethylenediamine (TMDA) were distilled before use. Fluorescein (Aldrich Co.) was recrystallized from pyridine. Other reagents were used as received (Aldrich Co.).

\section{Monomer synthesis}

Monomer 3: To a solution of $0.05 \mathrm{~mol}$ fluorescein (1) in $150 \mathrm{ml} \mathrm{N}$-methylpyrrolidone $0.1 \mathrm{~mol}$ anhydrous $\mathrm{K}_{2} \mathrm{CO}_{3}$ and $0.15 \mathrm{~mol}$ propargyl bromide were added and the reaction mixture was stirred at $80-90^{\circ} \mathrm{C}$ for 48 hours. The reaction mixture was cooled and poured into water. The precipitate formed was filtered off, washed with water and recrystallized twice from 2-propanol to give compound 3 with a yield of $83 \% . T_{\mathrm{m}}=189^{\circ} \mathrm{C}$. IR $\left(\mathrm{cm}^{-1}\right) 3290$, $3190 \quad(\equiv \mathrm{C}-\mathrm{H}), \quad 3080-3030 \quad(=\mathrm{C}-\mathrm{H}, \quad \mathrm{C}-\mathrm{H}$ arom), 2950 (C-H aliph.), 2120, $2110(\mathrm{C} \equiv \mathrm{CH})$, 1740 ( $\mathrm{C}=\mathrm{O}$ ester $), 1643$ ( $\mathrm{C}=\mathrm{O}$ ketone), 1597, $1510\left(\mathrm{C}=\mathrm{C}\right.$, arom). ${ }^{1} \mathrm{H}$ NMR, $\left(\mathrm{CDCl}_{3}\right), 2.27$ $\left(\mathrm{t}, 1 \mathrm{H}, \mathrm{HC} \equiv \mathrm{C}-\mathrm{CH}_{2}-\mathrm{OAr}\right), 2.55(\mathrm{t}, 1 \mathrm{H}, \mathrm{HC} \equiv$ $\left.\mathrm{C}-\mathrm{CH}_{2}-\mathrm{OOC}\right), 4.52\left(\mathrm{~d}, 2 \mathrm{H}, \mathrm{HC} \equiv \mathrm{C}-\mathrm{CH}_{2}-\right.$ $\mathrm{OAr}), \quad 4.54\left(\mathrm{~d}, \quad 2 \mathrm{H}, \quad \mathrm{HC} \equiv \mathrm{C}-\mathrm{CH}_{2}-\mathrm{OOC}\right)$, $6.38-8.32$ (m, 10H, olefin., arom.). ${ }^{13} \mathrm{C} \mathrm{NMR}$ $\left(\mathrm{CDCl}_{3}\right), 52.86 \quad\left(\mathrm{HC} \equiv \mathrm{C}-\mathrm{CH}_{2}-\mathrm{OAr}\right), 56.13$ $\left(\mathrm{HC} \equiv \mathrm{C}-\mathrm{CH}_{2}-\mathrm{OOC}\right), \quad 75.35 \quad\left(\mathrm{HC} \equiv \mathrm{C}-\mathrm{CH}_{2}-\right.$ OAr), $76.18\left(\mathrm{HC} \equiv \mathrm{C}-\mathrm{CH}_{2}-\mathrm{OOC}\right), 77.22$ $\left(\mathrm{HC} \equiv \mathrm{C}-\mathrm{CH}_{2}-\mathrm{OAr}\right), 77.47\left(\mathrm{HC} \equiv \mathrm{C}-\mathrm{CH}_{2}-\right.$ OOC), 101.71, 102.23, 105.98, 113.73, 115.55, $118.29,126.32,128.99,129.88,130.25,130.74$, $131.48,133.17,134.68,149.41,154.12,158.97$, 161.81 (all ring carbons), 164.57 (ester carbonyl), 185.86 (ketone carbonyl). Visible spectra $\left(\lambda_{\max }, \mathrm{nm}\right) 509,460,435$. Elemental Analysis. Calcd for $\mathrm{C}_{26} \mathrm{H}_{16} \mathrm{O}_{5}: \mathrm{C}, 76.46 \% ; \mathrm{H}$, $3.95 \%$. Found: C, $75.96 \%$; H, $4.01 \%$.

Monomer 4 (scheme 3) was prepared according to the literature ${ }^{12}$ with $68 \%$ yield $T_{\mathrm{m}}=41^{\circ} \mathrm{C}$.

\section{Polymerization}

Polymer 2. To $1.2 \mathrm{~g}(10 \mathrm{mmol})$ of freshly distilled $\mathrm{SOCl}_{2} 15 \mathrm{ml}$ pyridine were added at room temperature under nitrogen flow. After $20 \mathrm{~min}$ stirring $3 \mathrm{~g}(9.3 \mathrm{mmol})$ fluorescein dissolved in $15 \mathrm{ml}$ pyridine were added to the 

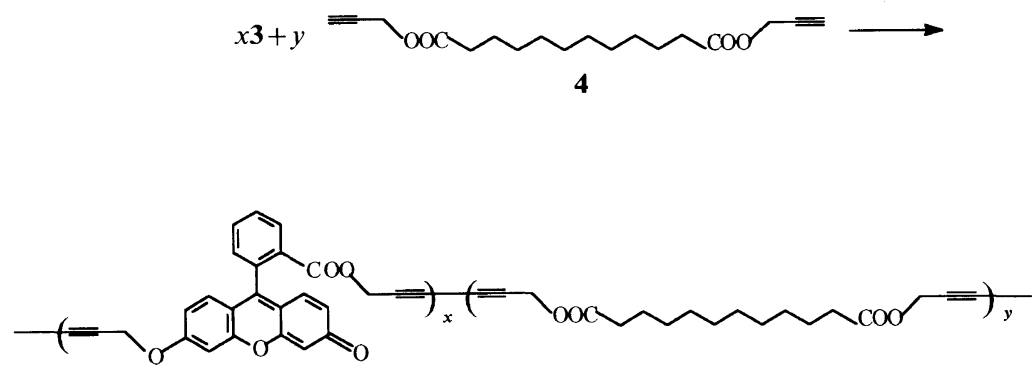

$\begin{array}{ccl}\text { Copolymer } & \text { X } & \mathrm{Y} \\ \mathbf{5 a} & 0.02 & 0.98 \\ \mathbf{5 b} & 0.1 & 0.90 \\ \mathbf{5 c} & 0.50 & 0.50 \\ \mathbf{5 d} & 0.70 & 0.30 \\ \mathbf{5 e} & 1.00 & 0\end{array}$

Scheme 3.

solution and the reaction mixture was stirred for 6 hours under nitrogen. After cooling, the reaction mixture was poured into acidified $\mathrm{MeOH}$, the polymer precipitated was filtered off, washed with $\mathrm{MeOH}$ and dried in vacuum at room temperature. Yield $85 \%$. IR $\left(\mathrm{cm}^{-1}\right)$ 3085-3020 (= C-H, C-H arom), $1740(\mathrm{C}=\mathrm{O}$ ester), $1639(\mathrm{C}=\mathrm{O}$ ketone $), 1587,1510(\mathrm{C}=\mathrm{C}$, arom). ${ }^{13} \mathrm{C}$ NMR, (dimethyl sulfoxide- $d_{6}$ (DMSO- $d_{6}$ ) 102.21, 102.83, 106.08, 114.65, $115.50,117.99,126.30,128.00,130.76,130.25$, $130.67,131.12,132.91,134.68,150.01,159.08$, 162.11, (all ring carbons), 166.77 (ester carbonyl), 185.96 (ketone carbonyl). Visible spectra $\left(\lambda_{\max }, \mathrm{nm}\right) 510,460,435$. Elemental Analysis. Calcd for $\left(\mathrm{C}_{20} \mathrm{H}_{10} \mathrm{O}_{5}\right)_{n}$ : C, $72.73 \%$; H, 3.05\%. Found: C, 73.06; H, 3.06\%.

The copolymers $\mathbf{5 a}, \mathbf{5 b}, \mathbf{5 c}, \mathbf{5 d}$, and $\mathbf{5 e}$ were prepared by oxidative coupling reactions of monomers 3 and 4. A typical example of copolymerization is shown below.

The mixture $(10 \mathrm{mmol})$ of monomers 3 and 4 was dissolved in $10 \mathrm{ml}$ ODCB at $70^{\circ} \mathrm{C}, 0.05 \mathrm{~g}$ of $\mathrm{CuCl}$ and $0.5 \mathrm{ml}$ of TMDA were added, and the mixture was stirred for 2 hours at $70-75^{\circ} \mathrm{C}$ under an oxygen atmosphere. The reaction mixture was poured into methanol acidified with $\mathrm{HCl}$. The precipitate was filtered off, washed with methanol, water and dried until constant weight at room temperature under vacuum. IR $\left(\mathrm{cm}^{-1}\right) 3080-3020(=\mathrm{C}-\mathrm{H}, \mathrm{C}-\mathrm{H}$ arom), 2950-2850 (C-H aliph., except 5e), $2220,2160(\mathrm{C} \equiv \mathrm{C}-\mathrm{C} \equiv \mathrm{C}-), 1740(\mathrm{C}=\mathrm{O}$ ester $)$, $1640(\mathrm{C}=\mathrm{O}$ ketone $), 1600,1510(\mathrm{C}=\mathrm{C}$, arom $)$. Elemental analysis and inherent viscosity data of the copolymers are presented in Table I.

Measurements. Inherent viscosities were measured at $25^{\circ} \mathrm{C}$ either in $\mathrm{CDCl}_{3}$ or pyridine (in the case of 2). DSC measurements were performed at a heating rate of $20^{\circ} \mathrm{C} \mathrm{min}^{-1}$ under nitrogen with a du Pont 2100. FT-IRspectra were taken using a Nikolet $510 p$ spectrometer. UV-visible spectra were taken using a UV-260 Shimadzu in chloroform or in the solid films. ${ }^{1} \mathrm{H}$ NMR and ${ }^{13} \mathrm{C}$ NMR spectroscopy were performed with a Varian at 300 and $75.5 \mathrm{MHz}$ respectively in $\mathrm{CDCl}_{3}$ or DMSO- $d_{6}$ with TMS as the internal standard. X-Ray diffractometry was performed using a Siemens D-500 diffractometer with $\mathrm{Cu}-K_{\alpha}$ radiation of 
Table I. Elemental analysis and inherent viscosity data $\left(\eta_{\text {inh }}\right)$ data of copolymers $\mathbf{5 a}-\mathbf{5 e}$

\begin{tabular}{cllcl}
\hline Copolymer & \multicolumn{2}{c}{$\begin{array}{c}\text { Calcd for } x-\left(\mathrm{C}_{26} \mathrm{H}_{14} \mathrm{O}_{5}\right)-y- \\
\left(\mathrm{C}_{\mathbf{1 8}} \mathrm{H}_{24} \mathrm{O}_{4}\right)\end{array}$} & & $\begin{array}{c}\left(\eta_{\text {inh }}\right) \\
\text { in dl g }\end{array}$ \\
\hline $\mathbf{5 a}$ & $x=0.02, y=0.98$ & $\mathrm{C}, 71.07 \% ; \mathrm{H}, 7.86 \%$ & 0.67 & $\mathrm{C}, 70.98 \% ; \mathrm{H}, 7.83 \%$ \\
$\mathbf{5 b}$ & $x=0.10, y=0.90$ & $\mathrm{C}, 71.77 \% ; \mathrm{H}, 7.37 \%$ & 0.59 & $\mathrm{C}, 71.93 \% ; \mathrm{H}, 7.21 \%$ \\
$\mathbf{5 c}$ & $x=0.50, y=0.50$ & $\mathrm{C}, 74.35 \% ; \mathrm{H}, 5.39 \%$ & 0.51 & $\mathrm{C}, 73.99 \% ; \mathrm{H}, 5.41 \%$ \\
$\mathbf{5 d}$ & $x=0.70, y=0.30$ & $\mathrm{C}, 75.43 \% ; \mathrm{H}, 4.56 \%$ & - & $\mathrm{C}, 75.81 \% ; \mathrm{H}, 4.33 \%$ \\
$\mathbf{5 e}$ & $x=1.00, y=0$ & $\mathrm{C}, 76.84 \% ; \mathrm{H}, 3.47 \%$ & - & $\mathrm{C}, 76.88 \% ; \mathrm{H}, 3.27 \%$ \\
\hline
\end{tabular}

$1.540 \AA$. The degree of crystallinity was calculated using program SOCABIM V. 3.0. This program gave the best-fit smooth curve to the diffractogram corresponding to the curve of the diffractogram of amorphous part of the sample, and therefore the ratio of the area under the calculated smooth curve to the area under experimental diffractogram was considered the proportion of the amorphous part of the sample. Photoluminescence was measured using a Perkin-Elmer LS-2 fluorimeter in $\mathrm{CHCl}_{3}$ solution or in solid film with excitation at $310 \mathrm{~nm}$.

\section{RESULTS AND DISCUSSION}

The direct polycondensation technique ${ }^{13}$ was used to prepare polymers directly from fluorescein under mild conditions (scheme 1). Polymer $\mathbf{2}$ had a rather poor solubility because of its rigid structure and was "reasonably" soluble only in pyridine and DMSO. The inherent viscosity of polymer 2 was found 0.39 $\mathrm{dl}^{-1}$ suggesting that the molecular weight is not high. This may be due to the presence of a small amount of tautomer 6 in fluorescein which terminates the polycondensation.

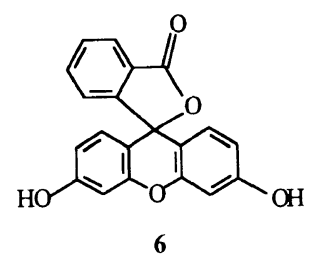

However, good quality transparent films could be cast from the pyridine solution. They were somewhat brittle when removed from the support. The IR spectra of polymer 2 contained absorption bands at 1740 and $1640 \mathrm{~cm}^{-1}$ corresponding to the ester and ketone carbonyl, respectively. The ${ }^{13} \mathrm{C}$ NMR spectra showed peaks at 166.77 and $185.96 \mathrm{ppm}$ corresponding to ester and ketone carbons, respectively. The visible spectra of the polymer 2 matched that of fluorescein, thus confirming that the chromophore in both cases should be the same.

Scheme 2 shows the synthesis of monomer 3. This is a one step reaction which gives the monomer in high yield. The structure of the monomer was confirmed by IR, ${ }^{1} \mathrm{H}$ NMR, ${ }^{13} \mathrm{C}$ NMR, visible spectra, and elemental analysis data. Similar to polymer 2 , the visible spectrum of monomer 3 matched that of fluorescein. The oxidative polymerization of monomer 3 (Scheme 3) was carried out at $70-75^{\circ} \mathrm{C}$ in ODCB in the presence of the CuCl-TMDA complex which is known to give good results for nonpolar bis-acetylenes. ${ }^{14}$ However, in the case of the homopolymerization of monomer 3, the polymer started to precipitate in a few minutes after starting polymerization. The resulting polymer $\mathbf{5 e}$ was insoluble in common solvents because of its rigid structure. Therefore, the copolymerization of monomer 3 with the more flexible monomer 4 was carried out to improve the solubility of fluoresceincontaining polymers. Copolymers with different ratios of the flexible monomer 3 were synthesized (Scheme 3). Copolymers containing up to $50 \mathrm{~mol} \%$ of monomer 3 (5a, $5 \mathbf{b}$, and 5c) were soluble in chloroform. Copolymer $5 \mathbf{d}$ containing $70 \mathrm{~mol} \%$ of monomer 3 was 


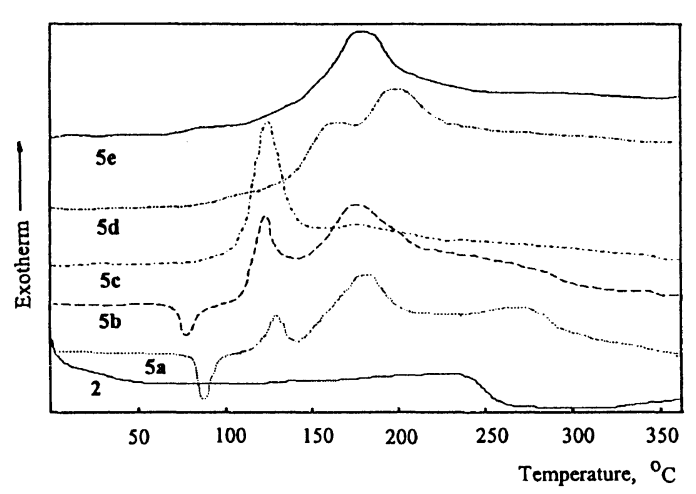

Figure 1. DSC curves of polymer 2 and copolymers $5 \mathbf{a}-5 \mathbf{e}$.

insoluble in common solvents.

Figure 1 shows the DSC curves of polymers synthesized. Polymer 2 showed $T_{\mathrm{g}}$ around $250^{\circ} \mathrm{C}$. Copolymers $\mathbf{5 a}-\mathbf{5 d}$ showed more complicated DSC curves. Copolymers $\mathbf{5 a}$, and $\mathbf{5 b}$, exhibited endotherms corresponding to the melting transition at 81.6 and $74.2^{\circ} \mathrm{C}$, respectively. Copolymers $5 \mathbf{c}, 5 \mathbf{d}$, and $5 \mathbf{e}$ showed no melting transition any more because the high concentration of the rigid comonomer 3 increased $T_{\mathrm{m}}$ of the copolymers above the temperature at the beginning of cross-linking. It is noteworthy that the homopolymer from monomer 4 had a melting transition at $84^{\circ} \mathrm{C},{ }^{12}$ higher than those of copolymers $\mathbf{5 a}$ and $\mathbf{5 b}$ which suggests a random structure of the copolymers. All copolymers, except 5e, showed two exotherms with maxima around 135$170^{\circ} \mathrm{C}$ and $190-210^{\circ} \mathrm{C}$ (polymer 5e showed only one exotherm with a maximum around $210^{\circ} \mathrm{C}$ ). The origin of the low temperature exotherm was studied by FT-IR spectroscopy using copolymer $\mathbf{5 c}$ where the exotherm was most pronounced. When heated to $150^{\circ} \mathrm{C}$ (the region between two exotherms) the absorption bands at 2220 and $2160 \mathrm{~cm}^{-1}$ corresponding to diacetylenic stretching almost disappeared. Similar to diacetylenic stretching, the absorption band at $750 \mathrm{~cm}^{-1}$ corresponding to the out of plane $=\mathrm{CH}$ deformation vibrations of cis-substituted double bond of the fluorescein

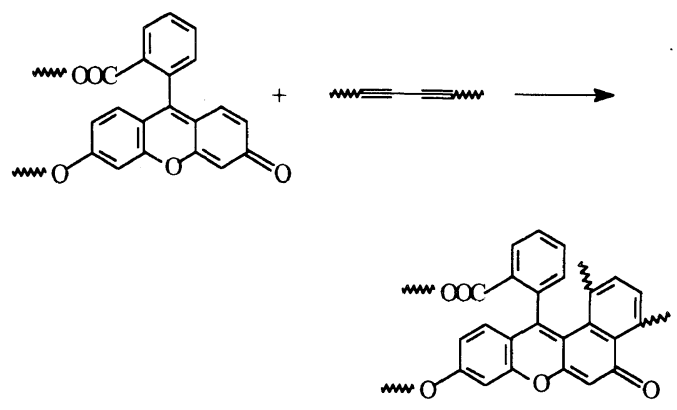

Scheme 4.

moiety also completely disappeared after thermal treatment. At the same time, increase in the intensity of $\mathrm{C}-\mathrm{H}$ aromatic stretching around $3050 \mathrm{~cm}^{-1}$ was observed. Considering these results, it may be assumed that cyclization reaction takes place, as shown in Scheme 4, which corresponds to the low temperature exotherm. With further heating to $210^{\circ} \mathrm{C}$ the absorption bands at 2220 and $2160 \mathrm{~cm}^{-1}$ due to stretching of diacetylenic groups, completely disappeared. Therefore, the high temperature exotherm may be due to thermal crosspolymerization of the rest of the diacetylenic groups. The peak maximum of the low temperature exotherm shifted to high temperature with the comonomer 3 content, and in the case of polymer $\mathbf{5 e}$, the low temperature exotherm coincided with the high temperature one. The reason for this may be increase in the rigidity of the polymer chain with the ratio of comonomer 3.

According to X-ray diffraction data, polymer 2 was almost totally amorphous. The calculated degree of crystallinity was $3.3 \%$. Diacetylene-containing copolymers were more crystalline, the calculated degrees of crystallinity being $33.2,32.5,11.9,24.3$, and $14.7 \%$ for copolymers $\mathbf{5 a}, \mathbf{5 b}, \mathbf{5 c}, \mathbf{5 d}$, and $\mathbf{5 e}$, respectively. The degree of crystallinity decreased as ratio of comonomers became equimolar; this is characteristic random copolymers. However, this was not observed in the case of $\mathbf{5 d}$ due to large difference in the rigidity between comonomers 3 and 4. 


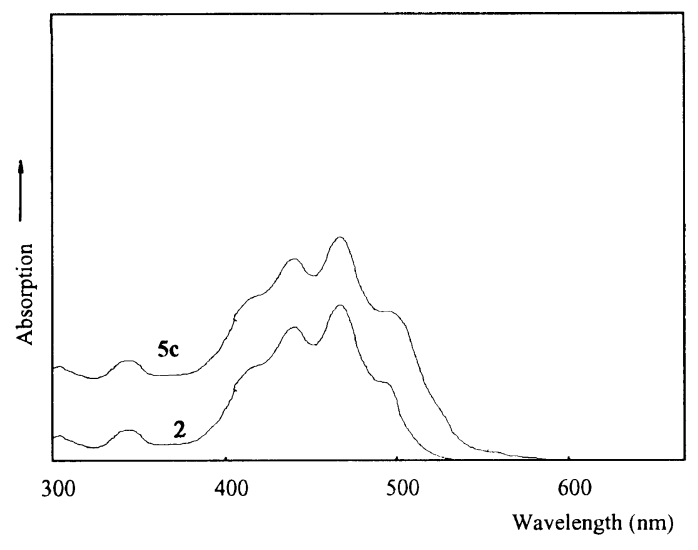

Figure 2. Solution visible absorption spectra of polymer 2 and copolymer $\mathbf{5 c}$.

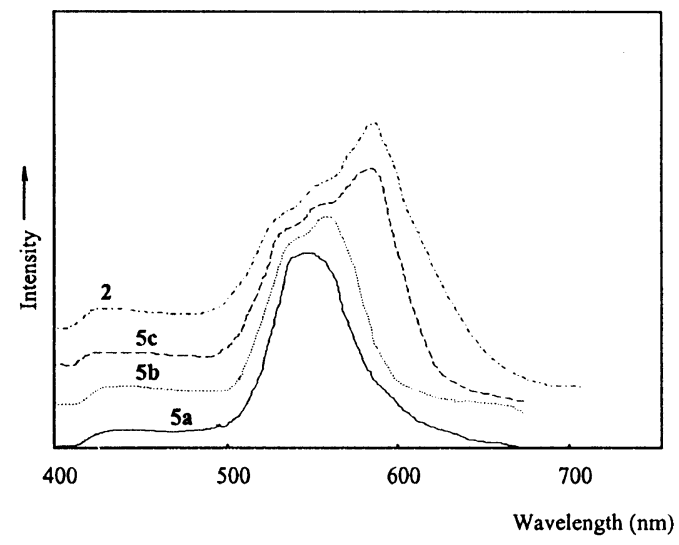

Figure 3. Luminescence spectra of polymer 2 and copolymers $\mathbf{5 a}-\mathbf{5 e}$.

All polymers showed identical absorption bands in the visible region due to fluorescein chromophore. Apparently, the position of the absorption maxima does not depend on the fluorescein ratio in the polymers. Examples of visible absorption spectra of chloroform solutions of polymer $\mathbf{2}$ and of copolymer $\mathbf{5 c}$ are shown in Figure 2.

Figure 3 shows the spectra of luminescence of diluted $\left(10^{-3} \mathrm{moll}^{-1}\right)$ chloroform solutions of polymer $\mathbf{2}$ and copolymers $\mathbf{5 a}, \mathbf{5 b}$, and $\mathbf{5 c}$. In the region of the $400-500 \mathrm{~nm}$ a shoulder could be seen due to reabsorption of emitted light by fluorescein moieties. The appearance

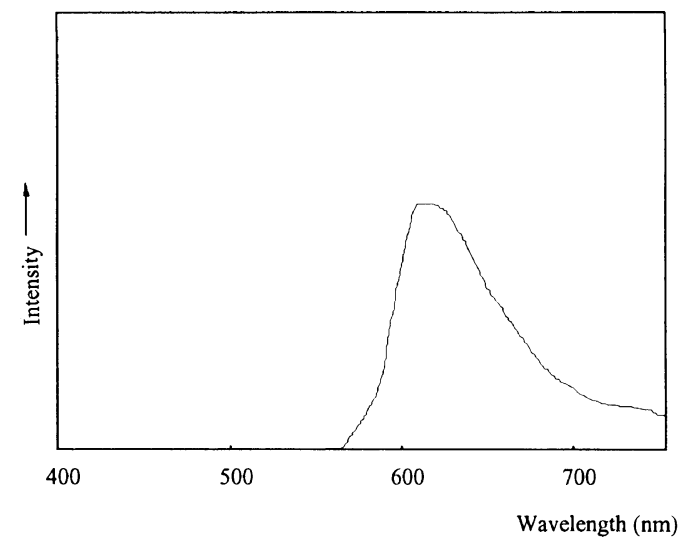

Figure 4. Luminescence spectra of the solid film of copolymer $\mathbf{5 c}$.

of luminescence spectra depends on the concentrations of fluorescein moieties in the polymer chain. Thus, the spectra of copolymer 5a which contains $2 \mathrm{~mol} \%$ fluorescein moieties showed the only maximum at $544 \mathrm{~nm}$, whereas the spectra of copolymers $\mathbf{5 b}$ and $\mathbf{5 c}$ showed additional maxima in the long-wavelength region, at 560,568 , and $588 \mathrm{~nm}$, respectively.

In the case of copolymer $\mathbf{5 a}$, the chromophore moieties were separated because of low concentration in the polymer chain and the luminescence spectrum resembled that of the isolated chromophore. In the cases of copolymers $\mathbf{5 b}$ and especially $\mathbf{5 c}$ which have high concentrations of chromophore groups, the fluorescein moieties may interact with each other within one polymer chain. The longwavelength bands in the luminescent spectra of the copolymers $\mathbf{5 b}$ and $\mathbf{5 c}$ may probably be of excimer origin. When excited, the chromophore moiety $\left(\mathrm{A}^{*}\right)$ may form an excimer (AA)* with a cromophore moiety of the same chain in the ground state (A) which emits light at a longer wavelength than the separated chromophores moiety $\left(\mathrm{A}^{*}\right)$.

The luminescence spectra of solid films of polymer $\mathbf{2}$ and copolymers $\mathbf{5 a}-\mathbf{5 c}$ were measured. The maxima in the luminescent spectra of the solid films shift by $30-50 \mathrm{~nm}$ to longwave region as compared to polymer 
solutions and the position of the maxima does not depend on polymer composition. All polymers had luminescence maxima around $610 \mathrm{~nm}$. An example of luminescent spectra of the solid film of copolymer $\mathbf{5 c}$ is shown in Figure 4. This long wavelength shift may come from difference in polarization energy of $S_{0}$ and $S_{1}$ state of the fluorescein moiety in the solid state. This means that magnitude of stabilization of $S_{1}$ in the solid state is greater than that of $S_{0}$ because in the former case, polarizability is higher. Therefore the transition energy $S_{0} \leftrightarrow S_{1}$ decreases causing a longwavelength shift of luminescence maxima.

Preliminary $\left(\chi^{(3)}\right)$ values of polymer films were obtained using the picosecond laser consisting of a mode locked Quantel Nd: YAG laser with frequency doubled to $532 \mathrm{~nm}$. $\left(\chi^{(3)}\right)$ Values of copolymers increased with the fluorescein ratio and reached $3 \times 10^{-10}$ esu for copolymer $\mathbf{5 c}$.

Detailed studies on the luminescent and nonlinear optical properties of these polymers as well as of other new luminescent polymers which are being synthesized in our laboratory, will be published in the future.

Acknowledgments. The authors acknowledge the financial support of CONACyT
(Consejo Nacional de Ciencias y Tecnologia) under contract No. E-9406 (1994-1995). Thanks are also due to C. Vazquez and L. Baños for assistance in therm analysis and $\mathrm{X}$-ray diffractometry, respectively.

\section{REFERENCES}

1. W. Klopffer, J. Chem. Phys., 50, 2337 (1969).

2. G. E. Johnson, J. Chem. Phys., 62, 4697 (1975).

3. K. D. Rockwitz and H. Baessler, J. Chem. Phys., 70, 307 (1982).

4. S. E. Weber, Chem. Rev., 90, 1469 (1990).

5. M. A. Fox, W. E. Jones, and D. M. Watkins, Chem. Eng. News, 71, 38 (1993).

6. J. Guillet, Polymer Photophysics and Photochemistry, Cambridge University Press, New York, 1985.

7. M. A. Winnik, Acc. Chem. Res., 18, 83 (1985).

8. J. R. Dharia, K. F. Johnson, and J. B. Schlenoff, Macromolecules, 27, 5167 (1994).

9. S. Matsuo, N. Yakoh, S. Chino, M. Mitai, and S. Tagami, J. Polym. Sci., Polym. Chem. Ed., 32, 1071 (1994).

10. J. S. Hargreaves and S.E. Webber, Macromolecules, 18, 734 (1985).

11. M. A. Kramer, W. R. Tompkin, and R. W. Boyd, Phys. Rev. A, 34, 2026 (1986).

12. S. Fomine, S. Sanchez, and T. Ogawa, Polym. J., 27, 165 (1995).

13. F. Higashi, J. Polym. Sci., 24, 1697 (1986).

14. S. Fomin, R. Neyra, and T. Ogawa, Polym. J., 26, 845 (1994). 